\title{
Mechanisms for the formation of benzene in the atmosphere of Titan
}

\author{
E. H. Wilson ${ }^{1}$ and S. K. Atreya \\ Department of Atmospheric, Oceanic, and Space Sciences, University of Michigan at Ann Arbor, Ann Arbor, \\ Michigan, USA
}

\author{
A. Coustenis \\ LESIA, Observatoire de Paris, Meudon, France
}

Received 26 February 2002; revised 23 May 2002; accepted 25 June 2002; published 26 February 2003.

[1] Polycyclic aromatic hydrocarbons (PAHs) are important interstellar species, and their precursor benzene $\left(\mathrm{C}_{6} \mathrm{H}_{6}\right)$ has been detected in our solar system. In this study the possibility of benzene formation in the atmosphere of Titan is investigated. Benzene abundance in Titan's atmosphere is found to be rather highly dependent on the assumed mechanism for benzene production. Assuming reactions involved in this mechanism to proceed at the rate corresponding to $300 \mathrm{~K}$, a value of $5.4 \times 10^{-7}$ at $2 \times 10^{-5} \mathrm{mbar}$ is found for the mole fraction of benzene. The primary mechanism responsible for this benzene abundance involves the recombination of propargyl $\left(\mathrm{C}_{3} \mathrm{H}_{3}\right)$ radicals. A source of benzene molecules through ion chemistry in the upper atmosphere is also investigated. The inclusion of heavy cyclic ions results in little change in the $\mathrm{C}_{6} \mathrm{H}_{6}$ abundance at the peak in mole fraction, where $\left[\mathrm{C}_{6} \mathrm{H}_{6}\right]=3.6 \times 10^{5} \mathrm{~cm}^{-3}$, but does produce about a factor of 2 increase in the benzene mole fraction at the $10^{-6}$ mbar level $\left[\mathrm{C}_{6} \mathrm{H}_{6}\right]=1 \times 10^{4} \mathrm{~cm}^{-3}$. This produces a negligible change in $\mathrm{C}_{6} \mathrm{H}_{6}$ column abundance below this microbar level. In the stratosphere, Infrared Space Observatory (ISO) measurements of the benzene abundance have been fit by our nominal profile multiplied by a factor of $3.0 \pm 0.5$. Taking the lower value of this factor, the ISO fit corresponds to an altitude-dependent benzene profile with a value of $9.8 \times 10^{-11}$ at 1 mbar. Benzene profiles determined in this study suggest an important path for the formation of higher-order hydrocarbons, which may play a significant role in the formation of hazes in Titan's atmosphere. INDEX TERMS: 2419 Ionosphere: Ion chemistry and composition (0335); 6280 Planetology: Solar System Objects: Saturnian satellites; 5405 Planetology: Solid Surface Planets: Atmospheres - composition and chemistry; 0343 Atmospheric Composition and Structure: Planetary atmospheres (5405, 5407, 5409, 5704, 5705, 5707); 0322 Atmospheric Composition and Structure: Constituent sources and sinks; KEYWORDS: Titan, benzene formation, PAH, ISO observations, aromatic chemistry, propargyl

Citation: Wilson, E. H., S. K. Atreya, and A. Coustenis, Mechanisms for the formation of benzene in the atmosphere of Titan, J. Geophys. Res., 108(E2), 5014, doi:10.1029/2002JE001896, 2003.

\section{Introduction}

[2] In Titan's atmosphere, hydrocarbon chemistry propagation leads to the formation of ever-larger molecules through mechanisms such as acetylene polymerization, hydrogen chain addition, and radical recombination. Through the creation of polyacetylenes and heavy ionic compounds, the foundation for the formation of soot particles, associated with the hazardous air pollution evident in the Earth's atmosphere, is laid. Another prominent product that acts as building blocks of soot particles is polycyclic aromatic hydrocarbons (PAHs). These PAHs and soot particles are efficiently formed in combustion environments where reactions with large activation energies can proceed

\footnotetext{
${ }^{1}$ Now at NASA/Jet Propulsion Laboratory, Pasadena, California, USA.
}

Copyright 2003 by the American Geophysical Union. 0148-0227/03/2002JE001896 at a sufficient rate [Tielens and Charnley, 1997]. Besides near manufacturing plants, PAHs can also be found in the universe in carbon-rich, high-temperature environments such as circumstellar and carbon-rich protoplanetary nebulae [Clemett et al., 1994; Buss et al., 1993]. PAHs have also been found in laboratory-simulated planetary atmospheres, such as simulations of Jupiter and Titan [Sagan et al., 1993].

[3] The formation of benzene $\left(\mathrm{C}_{6} \mathrm{H}_{6}\right)$, the simplest aromatic hydrocarbon, represents a primary stage of PAH and soot formation. Through the completion of that first aromatic ring, the process of soot formation can be initiated due to the high stability of aromatic rings and their high tendency to soot [Tielens and Charnley, 1997]. Mechanisms involving addition of hydrocarbons, such as acetylene onto aromatic rings as well as attachment of other aromatic rings, have been proposed to characterize the growth process of PAHs [Wang and Frenklach, 1994, 1997; Bittner and Howard, 1981]. Formation of PAHs has also been hypothe- 
sized to occur through the pyrolysis of hydrocarbons [Frenklach and Feigelson, 1989] and through synthesis from shocked benzene [Mimura, 1995], which may have cosmochemical significance.

\section{Experimental Studies}

[4] The formation of benzene, itself, has undergone significant study. Various recent studies regarding rates of propargyl recombination

$$
\mathrm{C}_{3} \mathrm{H}_{3}+\mathrm{C}_{3} \mathrm{H}_{3} \stackrel{M}{\rightarrow} \mathrm{C}_{6} \mathrm{H}_{6},
$$

have been conducted. Morter et al. [1994] measured propargyl recombination at a rate of $1.2 \pm 0.2 \times 10^{-10}$ $\mathrm{cm}^{3} \mathrm{~s}^{-1}$, a rate five times larger than self-reactions of other unsaturated hydrocarbon radicals [Atkinson and Hudgens, 1999]. Atkinson and Hudgens [1999] and Fahr and Nayak [2000] measured (R1) in separate studies and obtained similar results of lower rates for (R1). This model uses the Fahr and Nayak rate of $4.0 \times 10^{-11} \mathrm{~cm}^{3} \mathrm{~s}^{-1}$. The Fahr and Nayak study also analyzed products for propargyl recombination. However, the aromatic variety, benzene, has not yet been positively identified as a product for this reaction. Fahr and Nayak presented yields for linear- $\mathrm{C}_{6} \mathrm{H}_{6} \quad\left(n-\mathrm{C}_{6} \mathrm{H}_{6}\right)$ isomers as

$$
\begin{array}{cc}
1,5 \text { - hexadiyne }\left(\mathrm{CHCCH}_{2} \mathrm{CH}_{2} \mathrm{CCH}\right) & 60 \% \\
1,2 \text { - hexadiene }-5 y n e\left(\mathrm{CH}_{2} \mathrm{CHCCH}_{2} \mathrm{CCH}\right) & 25 \%
\end{array}
$$$$
\text { unidentified isomer }
$$

Nevertheless, Miller and Melius [1992], who point out that $n-\mathrm{C}_{4} \mathrm{H}_{3}$ and $n-\mathrm{C}_{4} \mathrm{H}_{5}$ isomerize rapidly enough to $i-\mathrm{C}_{4} \mathrm{H}_{3}$ and $i-\mathrm{C}_{4} \mathrm{H}_{5}$ to prevent significant formation of benzene through that route, propose propargyl recombination as the main source of benzene. Stein et al. [1990], using a conservative rate for benzene formation from propargyl recombination of $5.25 \times 10^{-15} \mathrm{~cm}^{3} \mathrm{~s}^{-1}$ in the flame study, reproduced the benzene formation rate of Westmoreland et al. [1989]. Wang and Frenklach [1997], in their extensive aromatic modeling study (WF) under combustion conditions, consider a rate for (R1) of $1.66 \times 10^{-13} \mathrm{~cm}^{3} \mathrm{~s}^{-1}$. WF also considers collisional isomerization of linear $-\mathrm{C}_{6} \mathrm{H}_{6}$ to benzene through RRKM calculations

$$
n-\mathrm{C}_{6} \mathrm{H}_{6}+\mathrm{H} \rightarrow \text { benzene }+\mathrm{H} \text {. }
$$

[5] Benzene can also be formed through addition-abstraction mechanisms. Cole et al. [1984] proposed that in a 1, 3butadiene $\left(1,3-\mathrm{C}_{4} \mathrm{H}_{6}\right)$ flame, the main route to benzene was provided by

$$
\begin{gathered}
1,3-\mathrm{C}_{4} \mathrm{H}_{5}+\mathrm{C}_{2} \mathrm{H}_{2} \rightarrow \mathrm{C}_{6} \mathrm{H}_{7} \\
\mathrm{C}_{6} \mathrm{H}_{7} \rightarrow c-\mathrm{C}_{6} \mathrm{H}_{7} \\
c-\mathrm{C}_{6} \mathrm{H}_{7} \rightarrow \mathrm{C}_{6} \mathrm{H}_{6}+\mathrm{H},
\end{gathered}
$$

where $1,3-\mathrm{C}_{4} \mathrm{H}_{5}$ was the product of $\mathrm{H}$ abstraction of the butadiene fuel. They also suggested $\mathrm{C}_{2} \mathrm{H}_{2}+\mathrm{C}_{2} \mathrm{H}_{3} \rightarrow \mathrm{C}_{4} \mathrm{H}_{5}$ as the main source of $\mathrm{C}_{4} \mathrm{H}_{5}$ for fuels other than butadiene.
This was later corroborated by Colket [1986] in shock tube pyrolysis and Harris et al. [1988] in ethylene flames for temperatures below $1500 \mathrm{~K}$ and $1000 \mathrm{~K}$, respectively. For vinylacetylene pyrolysis, Colket proposed the mechanism

$$
\begin{gathered}
\mathrm{C}_{4} \mathrm{H}_{4}+\mathrm{C}_{2} \mathrm{H}_{3} \rightarrow \mathrm{C}_{6} \mathrm{H}_{7} \\
\mathrm{C}_{6} \mathrm{H}_{7} \rightarrow c-\mathrm{C}_{6} \mathrm{H}_{7} \\
c-\mathrm{C}_{6} \mathrm{H}_{7} \rightarrow \mathrm{C}_{6} \mathrm{H}_{6}+\mathrm{H}
\end{gathered}
$$

as the preferred route for cyclization.

[6] Notwithstanding these combustion analyses conducted at temperatures of $1000 \mathrm{~K}$ and higher, the mechanisms which control aromatic chemistry at temperatures applicable to planetary atmospheres are still unclear. Callear and Smith [1986] provided the first analysis of many of the hydrogen and acetylene addition reactions at lower temperatures $(\mathrm{T} \leq 400 \mathrm{~K})$. Analysis of products ratios and modeling led to a determination of the hydrogenating reaction $\mathrm{C}_{2} \mathrm{H}_{3}+\mathrm{H}_{2} \rightarrow \mathrm{C}_{2} \mathrm{H}_{4}$ and rate coefficients for other chain-propagating reactions relative to $\mathrm{k}\left(\mathrm{C}_{2} \mathrm{H}_{3}+\mathrm{H}_{2}\right)$. Included in their model are the reactions

$$
\mathrm{C}_{4} \mathrm{H}_{5}+\mathrm{C}_{2} \mathrm{H}_{2} \rightarrow \mathrm{C}_{6} \mathrm{H}_{6}+\mathrm{H}
$$

$$
+\mathrm{M} \rightarrow \mathrm{C}_{6} \mathrm{H}_{7}
$$

for which each branching ratio is assumed to be about 0.5 . The benzene-forming pathway comes about via $\mathrm{H}$-abstraction from the cis $-\mathrm{C}_{6} \mathrm{H}_{7}^{*}$ radical, while the trans $-\mathrm{C}_{6} \mathrm{H}_{7}^{*}$ radical cannot cyclize and is stabilized. Weissman and Benson [1988] used the experimental data of Callear and Smith and transition-state theory to derive a rate expression for (R3a) of $4.17 \times 10^{-19} \mathrm{~T}^{1.8} \mathrm{e}^{-601 / \mathrm{T}} \mathrm{cm}^{3} \mathrm{~s}^{-1}$ over the temperature range of $300-1500 \mathrm{~K}$. However, in the analysis of Callear and Smith the assumption that all radical-radical reactions proceeded at the same rate was inadequate, as for example, the vinyl recombination rate proceeds at a much faster rate [Fahr et al., 1991].

[7] Westmoreland et al. [1989] screened possible mechanisms for benzene formation, as rate data for benzene formation were measured in a $\mathrm{C}_{2} \mathrm{H}_{2}$ flame. Using a Quantum Rice-Ramsperger-Kassel (QRRK) approach, Westmoreland et al. were able to identify four different channels for the addition of acetylene to butadienyl radical:addition/stabilization:

$$
\mathrm{C}_{4} \mathrm{H}_{5}+\mathrm{C}_{2} \mathrm{H}_{2} \rightarrow n-\mathrm{C}_{6} \mathrm{H}_{7}^{*} \rightarrow n-\mathrm{C}_{6} \mathrm{H}_{7}
$$

addition/decomposition:

$$
\mathrm{C}_{4} \mathrm{H}_{5}+\mathrm{C}_{2} \mathrm{H}_{2} \rightarrow n-\mathrm{C}_{6} \mathrm{H}_{7}^{*} \rightarrow n-\mathrm{C}_{6} \mathrm{H}_{6}+\mathrm{H}
$$

isomerization/stabilization:

$$
\mathrm{C}_{4} \mathrm{H}_{5}+\mathrm{C}_{2} \mathrm{H}_{2} \rightarrow n-\mathrm{C}_{6} \mathrm{H}_{7}^{*} \rightarrow c-\mathrm{C}_{6} \mathrm{H}_{7}^{*} \rightarrow c-\mathrm{C}_{6} \mathrm{H}_{7}
$$

isomerization/decomposition:

$$
\mathrm{C}_{4} \mathrm{H}_{5}+\mathrm{C}_{2} \mathrm{H}_{2} \rightarrow n-\mathrm{C}_{6} \mathrm{H}_{7}^{*} \rightarrow c-\mathrm{C}_{6} \mathrm{H}_{7}^{*} \rightarrow \text { benzene }+\mathrm{H}
$$




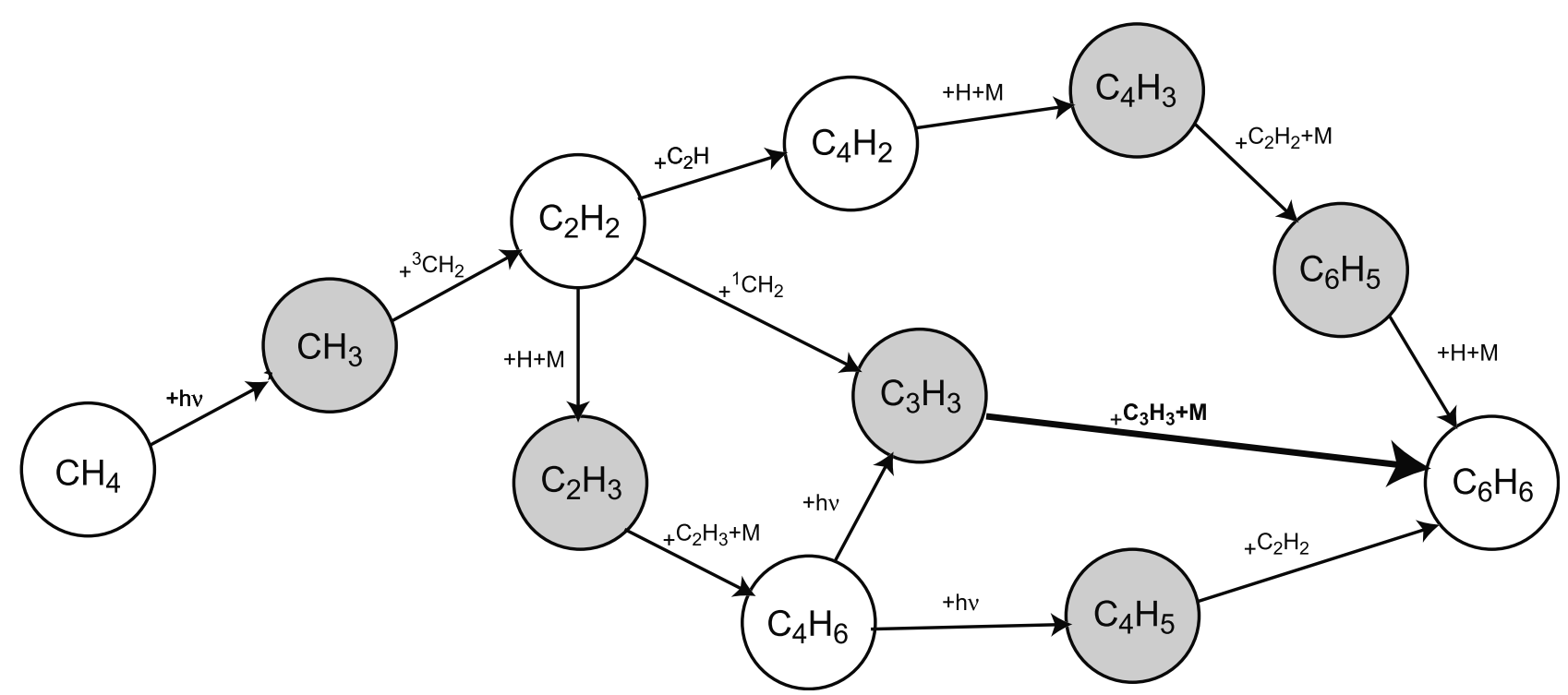

Figure 1. Schematic diagram of the mechanisms for benzene formation. The bold arrow represents the main pathway to benzene of propargyl recombination.

[8] Through this method, rate coefficients for the possible mechanisms and their pathways were fitted over the temperature range of $400-1600 \mathrm{~K}$, while experimental data showed that $\mathrm{C}_{2} \mathrm{H}_{2}+\mathrm{C}_{4} \mathrm{H}_{5}$ and $\mathrm{C}_{2} \mathrm{H}_{2}+\mathrm{C}_{4} \mathrm{H}_{3}$ and were responsible for benzene formation in the acetylene flame. From the QRRK calculations, the benzene-forming pathway was found to be the dominating pathway for $\mathrm{C}_{2} \mathrm{H}_{2}+\mathrm{C}_{4} \mathrm{H}_{5}$.

[9] $\mathrm{C}_{4} \mathrm{H}_{6}$ has also been proposed to be involved in the formation of benzene through reaction with metastable diacetylene $\left(\mathrm{C}_{4} \mathrm{H}_{2}^{*}\right)$ [Arrington et al., 1998]. Metastable diacetylene, which may contribute to the formation of larger polyynes in the atmosphere of Titan [Zwier and Allen, 1996], has been identified to play a role in the formation of aromatics, producing most prominently $\mathrm{C}_{6} \mathrm{H}_{6}$ and $\mathrm{C}_{8} \mathrm{H}_{6}$,

$$
\mathrm{C}_{4} \mathrm{H}_{2}^{*}+\mathrm{C}_{4} \mathrm{H}_{6} \rightarrow \mathrm{C}_{6} \mathrm{H}_{6}+\mathrm{C}_{2} \mathrm{H}+\mathrm{H}
$$

$$
\rightarrow \mathrm{C}_{8} \mathrm{H}_{6}+2 \mathrm{H}
$$

Although Arrington et al. were not able to determine absolute rate constants for this reaction, they did determine a relative rate constant of $1.21 \pm 0.07 \times \mathrm{k}\left(\mathrm{C}_{4} \mathrm{H}_{2}^{*}+\mathrm{C}_{4} \mathrm{H}_{2}\right)$.

[10] McEwan et al. [1999] introduced a mechanism for benzene formation involving small hydrocarbon ions. In interstellar gas, the abundance of hydrogen gas and atomic carbon along with its exposure to ionizing EUV radiation provides a pathway for ion-molecule $\mathrm{H}$-atom transfer and association reactions that can result in ring closure. The McEwan et al. mechanism culminates in the cyclization of the $\mathrm{C}_{6} \mathrm{H}_{5}{ }^{+}$ion followed by $\mathrm{H}_{2}$ addition and electron dissociative recombination to benzene

$$
\begin{aligned}
& c-\mathrm{C}_{6} \mathrm{H}_{5}^{+}+\mathrm{H}_{2} \rightarrow c-\mathrm{C}_{6} \mathrm{H}_{7}^{+}+h \nu \\
& c-\mathrm{C}_{6} \mathrm{H}_{7}^{+}+e^{-} \rightarrow \mathrm{C}_{6} \mathrm{H}_{6}+\mathrm{H} .
\end{aligned}
$$

[11] Despite the abundance of aromatic studies conducted at combustion temperatures, very few examinations of ben- zene formation have been conducted at temperatures relevant for atmospheric study. Recent detections of benzene in planetary atmospheres have rendered such examinations necessary and provided the need for inclusion of aromatic chemistry in atmospheric chemical models. Benzene has been detected in the north polar auroral region of Jupiter, with Kim et al. [1985] inferring a mixing ratio value for benzene of $2.0 \times 10^{-9}$. Wong et al. [2000] attribute the abundance of $\mathrm{C}_{6} \mathrm{H}_{6}$ in this region to the dissociation of methane through impact with high-energy precipitation electrons, which are enhanced in Jupiter's aurora, and subsequent dissociation recombination. Recently, benzene has been globally detected in the stratosphere of Jupiter and Saturn by the Infrared Space Observatory (ISO) [Encrenaz et al., 1999; Bézard et al., 2001], prompting modeling of benzene formation in Saturn's atmosphere by Moses et al. [2000].

\section{Model Results}

[12] In order to gather insight into the photochemical origin of Titan's opaque haze layer, we include the initiation of aromatic chemistry in our photochemical model, focusing on the formation of benzene. Our model is described by Wilson and Atreya [2000], extending from the surface to $1600 \mathrm{~km}$, with the inclusion of ion chemistry from Anicich and McEwan [1997] and photoelectrons, assuming a solar zenith angle of 60 degrees and no magnetospheric input (T. Cravens, personal communication, 2001). Radiative transfer of photons from 50-3000 $⿱$ has also been included. In this model, the Yelle et al. [1997] engineering model for the thermal profile is used. A schematic displaying the path toward benzene formation is shown in Figure 1. According to laboratory results, the main mechanisms for $\mathrm{C}_{6} \mathrm{H}_{6}$ formation are acetylene addition-hydrogen abstraction (R3) and propargyl recombination ( $\mathrm{R} 1)$. Benzene is the dominant product of (R3), according to Westmoreland et al. [1989], in the measured temperature range of $400-1600 \mathrm{~K}$. However, using their rate expressions and extrapolating down to colder temperatures indicative of Titan's atmosphere yields a 
Table 1. Descriptions of the Three Cases Studied and Rate Coefficients of the Main Reactions Used in Those Three Cases ${ }^{\mathrm{a}}$

\begin{tabular}{|c|c|c|c|}
\hline Case Descriptions & BEN1 & BEN2 & BEN3 (Nominal) \\
\hline \multirow[t]{2}{*}{ Rate coefficients } & $\begin{array}{l}\text { - Assumes benzene pathway } \\
\text { to be the main pathway of } \\
\mathrm{C}_{2} \mathrm{H}_{2}+\mathrm{C}_{4} \mathrm{H}_{5} \text { with } \\
\text { Westmoreland et al. }[1989] \text { rate } \\
\text { - Propargyl recombination } \\
\text { produces linear- } \mathrm{C}_{6} \mathrm{H}_{6} \text { with } \\
\text { Fahr and Nayak }[2000] \text { rate }\end{array}$ & $\begin{array}{l}\text { - Assumes all pathways of } \\
\mathrm{C}_{2} \mathrm{H}_{2}+\mathrm{C}_{4} \mathrm{H}_{5} \text { lead to } \\
\text { formation of benzene } \\
\text { - Propargyl recombination } \\
\text { leads exclusively to benzene }\end{array}$ & $\begin{array}{l}\text { - Full Wang and Frenklach } \\
{[1994,1997] \text { scheme for }} \\
\text { aromatic formation } \\
\text { - Fahr and Nayak [2000] } \\
\text { rate for linear-C } \mathrm{C}_{6} \text { production } \\
\text { from propargyl recombination } \\
\text { with benzene pathway from } \\
\text { Wang and Frenklach [1997] }\end{array}$ \\
\hline & $\begin{array}{l}\text { - Wang and Frenklach [1997] } \\
\text { rate for } \mathrm{C}_{6} \mathrm{H}_{6} \text { collisional } \\
\text { isomerization to benzene }\end{array}$ & & \\
\hline \multirow[t]{2}{*}{$\begin{array}{ll}\text { a) } \mathrm{C}_{3} \mathrm{H}_{3}+\mathrm{C}_{3} \mathrm{H}_{3} & \stackrel{\mathrm{M}}{\mathrm{M}} \mathrm{C}_{6} \mathrm{H}_{6} \\
\text { b) } & \stackrel{\mathrm{M}}{\rightarrow} n-\mathrm{C}_{6} \mathrm{H}_{6}\end{array}$} & $\begin{array}{c}\mathrm{k}_{1 \mathrm{a}}=0 \\
\mathrm{k}_{1 \mathrm{~b} 0}=8.8 \times 10^{-6} \mathrm{~T}^{-7.03} \mathrm{e}^{-1390 / \mathrm{T}} \\
\mathrm{k}_{1 \mathrm{~b} \infty}=4.0 \times 10^{-11}\end{array}$ & $\begin{array}{c}\mathrm{k}_{2 \mathrm{a} 0}=8.8 \times 10^{-6} \mathrm{~T}^{-7.03} \mathrm{e}^{-1390 / \mathrm{T}} \\
\mathrm{k}_{2 \mathrm{a} \infty}=4.0 \times 10^{-11} \\
\mathrm{k}_{2 \mathrm{~b}}=0\end{array}$ & $\begin{aligned} \mathrm{k}_{3 \mathrm{a} 0} & =2.6 \times 10^{-31} \\
\mathrm{k}_{3 \mathrm{a} \infty} & =1.7 \times 10^{-12} \\
\mathrm{k}_{3 \mathrm{~b} 0}=8.8 \times 10^{-6} \mathrm{~T}^{-7.03} \mathrm{e}^{-1390 / \mathrm{T}} & \mathrm{k}_{3 \mathrm{~b} \infty}=4.0 \times 10^{-11}\end{aligned}$ \\
\hline & $\begin{array}{c}\mathrm{k}_{1 \mathrm{~b} 0} \text { est. }^{\mathrm{b}} ; \\
\text { Fahr and Nayak }[2000] \\
\mathrm{k}_{1 \mathrm{a}}=1.4 \times 10^{-7} \mathrm{~T}^{-1.34} \mathrm{e}^{-1762 / \mathrm{T}}\end{array}$ & $\begin{array}{l}\mathrm{k}_{2 \mathrm{a0}} \text { est.; } \\
\text { Fahr and Nayak [2000] }\end{array}$ & $\begin{array}{c}\mathrm{k}_{3 \mathrm{~b} 0} \text { est. } \mathrm{s}^{\circ} \text { Wang and Frenklach } \\
{[1997] ; \text { Fahr and Nayak }[2000]} \\
\mathrm{k}_{3 \mathrm{a}}=1.4 \times 10^{-7} \mathrm{~T}^{-1.34} \mathrm{e}^{-1762 / \mathrm{T}}\end{array}$ \\
\hline $\begin{array}{l}\text { a) } n-\mathrm{C}_{6} \mathrm{H}_{6}+\mathrm{H} \\
\text { b) } \\
\stackrel{\rightarrow}{\rightarrow} n-\mathrm{C}_{6} \mathrm{H}_{6}+\mathrm{H} \\
\mathrm{H}_{7}\end{array}$ & $\begin{array}{c}\mathrm{k}_{1 \mathrm{~b} 0}=8.0 \times 10^{-31} \mathrm{~T}^{-0.52} \mathrm{e}^{-504 / \mathrm{T}} \\
\mathrm{k}_{1 \mathrm{~b} \infty}=1.1 \times 10^{-14} \mathrm{~T}^{0.86} \mathrm{e}^{-554 / \mathrm{T}} \\
\text { Wang and Frenklach }[1997]\end{array}$ & 0 & $\begin{array}{c}\mathrm{k}_{3 \mathrm{~b} 0}=8.0 \times 10^{-31} \mathrm{~T}^{-0.52} \mathrm{e}^{-504 / \mathrm{T}} \\
\mathrm{k}_{3 \mathrm{~b} \infty}=1.1 \times 10^{-14} \mathrm{~T}^{0.86} \mathrm{e}^{-554 / \mathrm{T}} \\
\text { Wang and Frenklach }[1997]\end{array}$ \\
\hline $\begin{array}{ll}\text { a) } \mathrm{C}_{4} \mathrm{H}_{3}+\mathrm{C}_{2} \mathrm{H}_{2} & \stackrel{\mathrm{M}}{\mathrm{M}} \mathrm{C}_{6} \mathrm{H}_{5} \\
\text { b) } & \stackrel{\rightarrow}{\rightarrow}-\mathrm{C}_{6} \mathrm{H}_{5}\end{array}$ & $\begin{array}{c}\mathrm{k}_{1 \mathrm{aa} 0}=3.3 \times 10^{-29} \mathrm{e}^{-740 / \mathrm{T}} \\
\mathrm{k}_{1 \mathrm{a} \infty}=5.5 \mathrm{~T}^{-3.89} \mathrm{e}^{-4635 / \mathrm{T}}\end{array}$ & $\begin{array}{c}\mathrm{k}_{2 \mathrm{a} 0}=3.3 \times 10^{-29} \mathrm{e}^{-740 / \mathrm{T}} \\
\mathrm{k}_{2 \mathrm{a} \infty}=5.5 \mathrm{~T}^{-3.89} \mathrm{e}^{-4635 / \mathrm{T}}\end{array}$ & $\begin{array}{l}\mathrm{k}_{3 \mathrm{a} 0}=1.3 \times 10^{10} \mathrm{~T}^{-12.77} \mathrm{e}^{-5888 / \mathrm{T}} \\
\mathrm{k}_{3 \mathrm{a} \infty}=2.8 \times 10^{-17} \mathrm{~T}^{0.47} \mathrm{e}^{-3020 / \mathrm{T}}\end{array}$ \\
\hline$\rightarrow \mathrm{C}_{6} \mathrm{H}_{4}+\mathrm{H}$ & $\mathrm{k}_{1 \mathrm{~b}}=0$ & $\mathrm{k}_{2 \mathrm{~b} 0}=3.3 \times 10^{-29} \mathrm{e}^{-740 / \mathrm{T}}$ & $\mathrm{k}_{3 \mathrm{~b} 0}=2.2 \times 10^{-24} \mathrm{~T}^{-2.66} \mathrm{e}^{-1711 / \mathrm{T}}$ \\
\hline \multirow[t]{2}{*}{ d) $\quad \rightarrow n-\mathrm{C}_{6} \mathrm{H}_{4}+\mathrm{H}$} & $\begin{array}{l}\mathrm{k}_{1 \mathrm{c}}=0 \\
\mathrm{k}_{1 \mathrm{~d}}=0\end{array}$ & $\begin{aligned} \mathrm{k}_{2 \mathrm{~b} \infty} & =2.9 \times 10^{-13} \mathrm{~T}^{-0.41} \mathrm{e}^{-2028 / \mathrm{T}} \\
\mathrm{k}_{2 \mathrm{c}} & =2.7 \times 10^{-15} \mathrm{~T}^{0.73} \mathrm{e}^{-6130 / \mathrm{T}} \\
\mathrm{k}_{2 \mathrm{~d}} & =4.9 \times 10^{-23} \mathrm{~T}^{3.33} \mathrm{e}^{-4841 / \mathrm{T}}\end{aligned}$ & $\begin{array}{c}\mathrm{k}_{3 \mathrm{~b} \infty}=4.8 \times 10^{-17} \mathrm{~T}^{1.40} \mathrm{e}^{-1158 / \mathrm{T}} \\
\mathrm{k}_{3 \mathrm{c}}=0.6 \mathrm{~T}^{-3.70} \mathrm{e}^{-3775 / \mathrm{T}} \\
\mathrm{k}_{3 \mathrm{~d}}=2.8 \times 10^{-29} \mathrm{~T}^{4.44} \mathrm{e}^{-3473 / \mathrm{T}}\end{array}$ \\
\hline & $\begin{array}{c}\mathrm{k}_{1 \mathrm{a} 0} \text { est. }^{\mathrm{c}} \text {; } \\
\text { Westmoreland et al. [1989] }\end{array}$ & $\begin{array}{c}\mathrm{k}_{2 \mathrm{a} 0} \text { est. }^{\mathrm{c}} ; \\
\text { Westmoreland et al. [1989] }\end{array}$ & Wang and Frenklach [1994] \\
\hline $\begin{aligned} \text { a) } \mathrm{C}_{4} \mathrm{H}_{5}+\mathrm{C}_{2} \mathrm{H}_{2} & \rightarrow \mathrm{C}_{6} \mathrm{H}_{6}+\mathrm{H} \\
\text { b) } & \rightarrow n-\mathrm{C}_{6} \mathrm{H}_{6}+\mathrm{H}\end{aligned}$ & $\begin{array}{c}\mathrm{k}_{1 \mathrm{a}}=3.2 \times 10^{-17} \mathrm{~T}^{1.47} \mathrm{e}^{-2471 / \mathrm{T}} \\
\mathrm{k}_{1 \mathrm{~b}}=0\end{array}$ & $\begin{array}{l}\mathrm{k}_{\mathrm{a}}=3.2 \times 10^{-17} \mathrm{~T}^{1.47} \mathrm{e}^{-2471 / \mathrm{T}} \\
\mathrm{k}_{\mathrm{b}}=1.9 \times 10^{-39} \mathrm{~T}^{7.84} \mathrm{e}^{-1027 / \mathrm{T}}\end{array}$ & $\begin{array}{l}\mathrm{k}_{3 \mathrm{a}}=3.5 \times 10^{-9} \mathrm{~T}^{-1.07} \mathrm{e}^{-2416 / \mathrm{T}} \\
\mathrm{k}_{3 \mathrm{~b}}=9.6 \times 10^{-16} \mathrm{~T}^{1.02} \mathrm{e}^{-5486 / \mathrm{T}}\end{array}$ \\
\hline$\stackrel{\mathrm{M}}{\mathrm{M}} \mathrm{C}_{6} \mathrm{H}_{7}$ & $\mathrm{k}_{1 \mathrm{c}}=0$ & $\mathrm{k}_{\mathrm{c} 0}=3.3 \times 10^{-29} \mathrm{e}^{-740 / \mathrm{T}}$ & $\mathrm{k}_{3 \mathrm{c} 0}=1.4 \times 10^{-22} \mathrm{~T}^{-4.21} \mathrm{e}^{-2013 / \mathrm{T}}$ \\
\hline$\stackrel{\mathrm{M}}{\rightarrow} n-\mathrm{C}_{6} \mathrm{H}_{7}$ & $k_{1,}=0$ & $\begin{array}{c}\mathrm{k}_{\mathrm{c} \infty}=8.3 \mathrm{~T}^{5.46} \mathrm{e}^{-2315 / \mathrm{T}} \\
\mathrm{k}_{\mathrm{d} 0}=3.3 \times 10^{-29} \mathrm{e}^{-740 / \mathrm{T}} \\
\mathrm{k}_{\mathrm{d} \infty}=1.9 \times 10^{-10} \mathrm{~T}^{-1.27} \mathrm{e}^{-1459 / \mathrm{T}} \\
\mathrm{k}_{2 \mathrm{a}}=\mathrm{k}_{\mathrm{a}}+\mathrm{k}_{\mathrm{b}}+\mathrm{k}_{\mathrm{c}}+\mathrm{k}_{\mathrm{d}}\end{array}$ & $\begin{array}{l}\mathrm{k}_{3 \mathrm{c} \infty}=8.0 \times 10^{-17} \mathrm{~T}^{0.35} \mathrm{e}^{-2365 / \mathrm{T}} \\
\mathrm{k}_{3 \mathrm{~d} 0}=1.2 \times 10^{-21} \mathrm{~T}^{-3.28} \mathrm{e}^{-5133 / \mathrm{T}} \\
\mathrm{k}_{3 \mathrm{~d} \infty}=6.1 \times 10^{-17} \mathrm{~T}^{1.33} \mathrm{e}^{-1057 / \mathrm{T}}\end{array}$ \\
\hline & Westmoreland et al. [1989] & $\begin{array}{l}\mathrm{k}_{\mathrm{c} 0}, \mathrm{k}_{\mathrm{d} 0} \text { est. }^{\mathrm{c}} ; \\
\text { Westmoreland et al. [1989] }\end{array}$ & Wang and Frenklach [1994] \\
\hline $\mathrm{C}_{6} \mathrm{H}_{5}+\mathrm{H} \stackrel{\mathrm{M}}{\rightarrow} \mathrm{C}_{6} \mathrm{H}_{6}$ & $\begin{array}{c}\mathrm{k}_{0}=1.8 \times 10^{28} \mathrm{~T}^{-16.3} \mathrm{e}^{-3526 / \mathrm{T}} \\
\mathrm{k}_{\infty}=1.66 \times 10^{-10} \\
\text { Wang and Frenklach }[1997]\end{array}$ & $\begin{array}{c}\mathrm{k}_{0}=1.8 \times 10^{28} \mathrm{~T}^{-16.3} \mathrm{e}^{-3526 / \mathrm{T}} \\
\mathrm{k}_{\infty}=1.66 \times 10^{-10} \\
\text { Wang and Frenklach }[1997]\end{array}$ & $\begin{array}{c}\mathrm{k}_{0}=1.8 \times 10^{28} \mathrm{~T}^{-16.3} \mathrm{e}^{-3526 / \mathrm{T}} \\
\mathrm{k}_{\infty}=1.66 \times 10^{-10} \\
\text { Wang and Frenklach }[1997]\end{array}$ \\
\hline
\end{tabular}

${ }^{a}$ Three-body reactions are calculated according to the expression $\mathrm{k}=\mathrm{k}_{0} \mathrm{k}_{8} \mathrm{M} /\left(\mathrm{k}_{0} \mathrm{M}+\mathrm{k}_{8}\right)$, where $\mathrm{M}=$ total number density.

${ }^{\mathrm{b}} \mathrm{k}_{0}=\mathrm{k}_{0}\left(\mathrm{CH}_{3}+\mathrm{CH}_{3}\right)$, estimated from $10 \times$ Slagle et al. [1988].

${ }^{c} \mathrm{k}_{0}=10 \times \mathrm{k}_{0}\left(\mathrm{C}_{2} \mathrm{H}_{2}+\mathrm{H}\right)$, estimated from Baulch et al. [1992].

different result. At $150 \mathrm{~K}$ the pathway yielding $n-\mathrm{C}_{6} \mathrm{H}_{7}$ has a rate constant 50 times that of benzene. In order to examine these possible mechanisms of ring closure, three different cases of benzene formation are considered as indicated in . BEN1 assumes that the dominant pathways in aromatic chemistry at the lowest temperature considered in the studies are, in fact, the primary pathways in the case of Titan. The benzene pathway is assumed to result from (R3) with the Westmoreland et al. [1989] rate expression. The molecule $n$ $\mathrm{C}_{6} \mathrm{H}_{6}$ is also assumed to be produced by propargyl recombination with the room temperature Fahr and Nayak [2000] rate and to be collisionally isomerized to benzene with the WF rate. In BEN2 benzene is taken to be the sole hydrocarbon product of (R1) and (R3). This would assume that the $\mathrm{C}_{6} \mathrm{H}_{6}$ and $\mathrm{C}_{6} \mathrm{H}_{7}$ isomers would be rapidly converted to benzene where it is stabilized. In BEN3 the full schemes of Westmoreland et al. and the relevant reactions in the full WF scheme are assumed to take place in Titan's atmosphere. This requires modeling of the rearranged isomers of intermediates, like $n-\mathrm{C}_{6} \mathrm{H}_{4}$ and $n-\mathrm{C}_{6} \mathrm{H}_{5}$, in addition to the intermediates themselves. In this case the Fahr and Nayak mechanism is used, producing $n-\mathrm{C}_{6} \mathrm{H}_{6}$, along with the benzene-producing mechanisms in WF, through recombination and isomerization. BEN3 provides a more detailed and complete calculation, and as discussed in section 4, the BEN3 profile provides the best match to ISO observations [Coustenis et al., 2003]. Thus, this most detailed case is adopted as the nominal profile. Loss of benzene due to photolysis [Rennie et al., 1998; Pantos et al., 1978; Yokoyama et al., 1990] and condensation [Weast et al., 1987] are also included in the calculations.

[13] Another issue involving the kinetics of aromatic chemistry is the large temperature dependence, in general, of these reactions below the range of temperatures they were measured for, due to the large activation energies inherent in these complexes. Typically photochemical modelers use given rate expressions to extrapolate to lower temperatures in the absence of measured data at these temperatures, with rates at these temperatures varying, in many cases, by as much as $2-3$ orders of magnitude from 

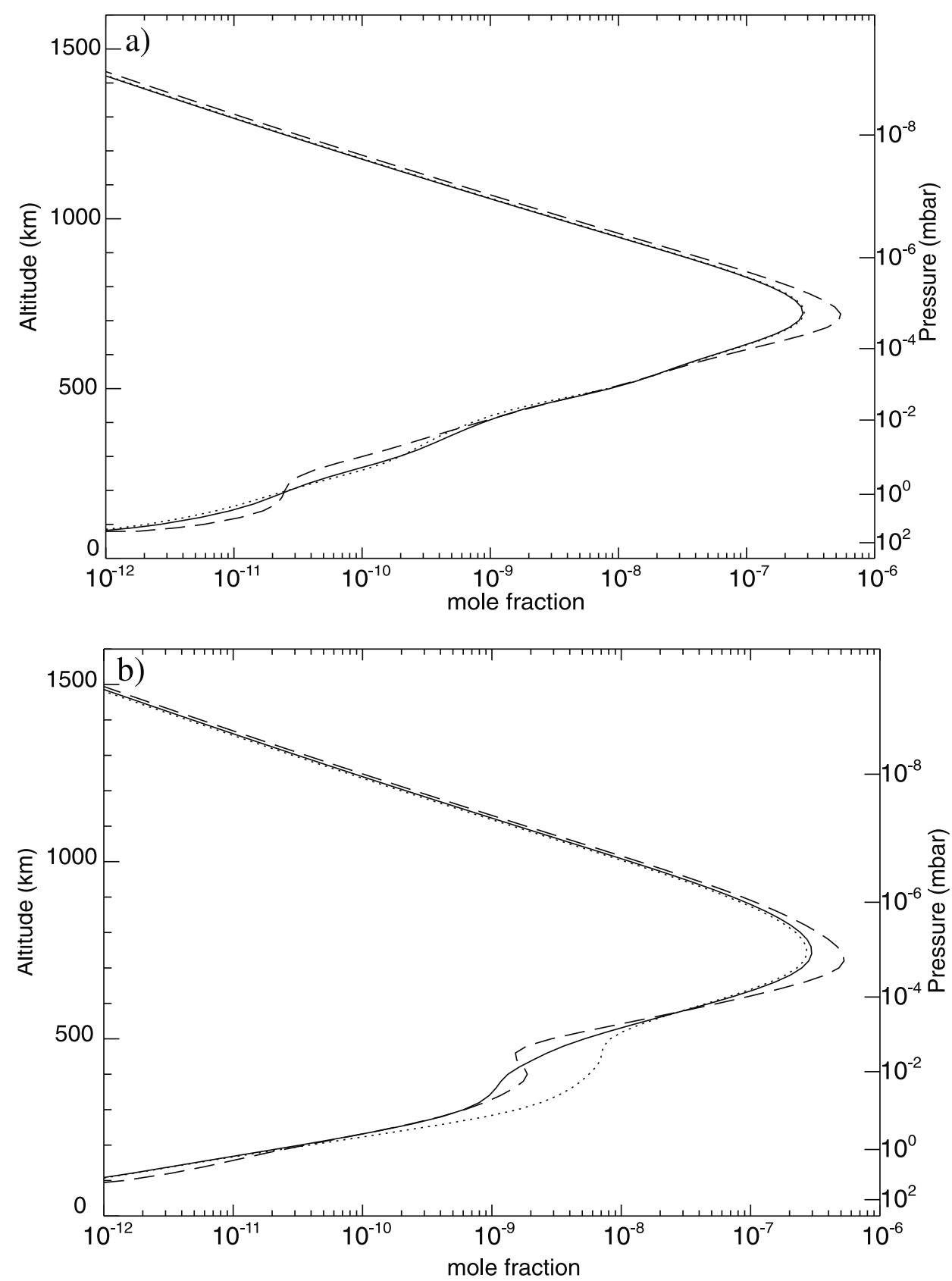

Figure 2. a) Abundance profile of $\mathrm{C}_{6} \mathrm{H}_{6}$ for the three cases of study under normal Titan temperature dependency conditions. b) $\mathrm{C}_{6} \mathrm{H}_{6}$ abundance profiles under nominal condition of aromatic rates calculated at $300 \mathrm{~K}$. The solid line represents BEN1, the dashed line represents BEN2, and the dotted line represents the nominal profile - BEN3.

the measured rate, usually conducted at room temperature. This practice has led to some modeling success, although there are exceptions. One example of this problem outside the realm of aromatic chemistry is the methyl radical $\left(\mathrm{CH}_{3}\right)$ recombination rate, where two theories obtain similar rates for methyl recombination at the measured temperatures $(\geq 300 \mathrm{~K})$, but vary widely for lower temperatures [Atreya et al., 1999]. Many of the reaction rates involved in aromatic chemistry used in this model were tabulated by Wang and Frenklach [1994, 1997] for which $300 \mathrm{~K}$ is the lowest applicable temperature. Below this temperature, rates in the fall-off region vary in most cases by $4-10$ orders of magnitude for this class of reactions. Owing to the lack of any test of the theory used to obtain these rate expressions for aromatic chemical reactions at lower temperatures and the very large discrepancies between obtained rates and the would-be rates at Titan-like temperatures the rates at $300 \mathrm{~K}$ are used for reactions involved in aromatic mechanisms.

[14] Figure 2a shows the benzene abundance profiles for the three cases under normal Titan temperature dependence, while Figure $2 \mathrm{~b}$ shows the benzene profiles for the aromatic rates at $300 \mathrm{~K}$. Figure $2 \mathrm{~b}$ shows an increase in benzene 
Table 2. Column Abundances of Benzene at Key Pressure Levels in the Atmosphere and the Benzene Condensation Fluxes for the Three Neutral Cases and the Ion Case That Includes the Ion Pathway to Benzene

\begin{tabular}{ccccc}
\hline $\begin{array}{c}\mathrm{C}_{6} \mathrm{H}_{6} \text { Column } \\
\text { Abundance, mbar }\end{array}$ & BEN1, cm ${ }^{-2}$ & BEN2, cm ${ }^{-2}$ & $\begin{array}{c}\text { BEN3, cm } \\
(\text { Nominal })\end{array}$ & Ion Case, $\mathrm{cm}^{-2}$ \\
\hline Peak $\left(1.3 \times 10^{-5}\right)$ & $1.2 \times 10^{12}$ & $1.8 \times 10^{12}$ & $1.1 \times 10^{12}$ & $1.4 \times 10^{12}$ \\
$10^{-3}$ & $1.6 \times 10^{13}$ & $2.1 \times 10^{13}$ & $1.6 \times 10^{13}$ & $1.7 \times 10^{13}$ \\
1 & $8.1 \times 10^{13}$ & $8.5 \times 10^{13}$ & $1.7 \times 10^{14}$ & $1.7 \times 10^{14}$ \\
3 & $8.6 \times 10^{13}$ & $9.1 \times 10^{13}$ & $1.8 \times 10^{14}$ & $1.8 \times 10^{14}$ \\
30 & $9.0 \times 10^{13}$ & $9.6 \times 10^{13}$ & $1.8 \times 10^{14}$ & $1.8 \times 10^{14}$ \\
& $7.6 \times 10^{5}$ & $1.7 \times 10^{6}$ & $7.1 \times 10^{5}$ & $7.1 \times 10^{5}$ \\
$\begin{array}{c}\text { Maximum condensation } \\
\text { flux }{ }^{\mathrm{a}} \mathrm{cm}^{-2} \mathrm{~s}^{-1}\end{array}$ & & & \\
\hline
\end{tabular}

${ }^{\mathrm{a}}$ See text.

stratospheric abundance of 2-5 times for the nominal case, BEN3, over the results in Figure 2a. The peak of benzene abundance under these conditions occurs at $720 \mathrm{~km}$, just below the level of unit optical depth level for methane, with a mixing ratio of $2.7 \times 10^{-7}$ for BEN1, $5.4 \times 10^{-7}$ for $\mathrm{BEN} 2$, and $2.4 \times 10^{-7} \mathrm{BEN} 3$. Benzene formation is dominated by propargyl recombination through the scheme

$$
\begin{aligned}
& 2\left(\mathrm{CH}_{4}+h v\right.\left.\rightarrow{ }^{1} \mathrm{CH}_{2}+\mathrm{H}_{2}\right) \\
& 2\left(\mathrm{C}_{2} \mathrm{H}_{2}+{ }^{1} \mathrm{CH}_{2}\right.\left.\rightarrow \mathrm{C}_{3} \mathrm{H}_{3}+\mathrm{H}\right) \\
& \mathrm{C}_{3} \mathrm{H}_{3}+\mathrm{C}_{3} \mathrm{H}_{3} \stackrel{\mathrm{M}}{\rightarrow}[n-] \mathrm{C}_{6} \mathrm{H}_{6} \\
& {\left[n-\mathrm{C}_{6} \mathrm{H}_{6}+\mathrm{H} \rightarrow \mathrm{C}_{6} \mathrm{H}_{6}+\mathrm{H}\right] } \\
& 2 \mathrm{C}_{2} \mathrm{H}_{2}+2 \mathrm{CH}_{4} \rightarrow \mathrm{C}_{6} \mathrm{H}_{6}+2 \mathrm{H}+\mathrm{H}_{2}
\end{aligned}
$$

accounting for $52 \%$ of non-recycled benzene formation. (S1) is driven by methane photolysis, which places the benzene peak near the level of unit optical depth of methane photolysis. The distribution of $\mathrm{C}_{6} \mathrm{H}_{6}$ into $n-\mathrm{C}_{6} \mathrm{H}_{6}$ and benzene accounts for the decrease in peak benzene abundance in BEN1 and BEN3.

[15] Column abundances for $\mathrm{C}_{6} \mathrm{H}_{6}$ are shown in Table 2. The condensation flux is an upper limit, calculated by taking the column production-loss $(\mathrm{P}-\mathrm{L})$ rate assuming no $\mathrm{C}_{6} \mathrm{H}_{6}$ condensation and subtracting it from the $(\mathrm{P}-\mathrm{L})$ rate with $\mathrm{C}_{6} \mathrm{H}_{6}$ condensation. Besides condensing out onto the surface of Titan, benzene can also serve as a precursor to the formation of haze particles in Titan's atmosphere, as discussed by E. H. Wilson and S. K. Atreya (Chemical sources of haze formation in Titan's atmosphere, submitted to Planetary and Space Science, 2003).

[16] In the millibar region, propargyl recombination is the primary source in the BEN1 profile, this time through the pressure-induced scheme

$$
\begin{gathered}
4\left(\mathrm{C}_{2} \mathrm{H}_{2}+\mathrm{H} \stackrel{\mathrm{M}}{\rightarrow} \mathrm{C}_{2} \mathrm{H}_{3}\right) \\
2\left(\mathrm{C}_{2} \mathrm{H}_{3}+\mathrm{C}_{2} \mathrm{H}_{3} \stackrel{\mathrm{M}}{\rightarrow} \mathrm{C}_{4} \mathrm{H}_{6}\right) \\
2\left(\mathrm{C}_{4} \mathrm{H}_{6}+h v \rightarrow \mathrm{C}_{3} \mathrm{H}_{3}+\mathrm{CH}_{3}\right) \\
\mathrm{CH}_{3}+\mathrm{CH}_{3} \stackrel{\mathrm{M}}{\rightarrow} \mathrm{C}_{2} \mathrm{H}_{6} \\
\mathrm{C}_{3} \mathrm{H}_{3}+\mathrm{C}_{3} \mathrm{H}_{3} \stackrel{M}{\rightarrow} n-\mathrm{C}_{6} \mathrm{H}_{6} \\
n-\mathrm{C}_{6} \mathrm{H}_{6}+\mathrm{H} \rightarrow \mathrm{C}_{6} \mathrm{H}_{6}+\mathrm{H} \\
4 \mathrm{C}_{2} \mathrm{H}_{2}+4 \mathrm{H} \rightarrow \mathrm{C}_{6} \mathrm{H}_{6}+\mathrm{C}_{2} \mathrm{H}_{6}
\end{gathered}
$$

which converts acetylene into benzene and ethane. However, acetylene addition does provide a significant source through the mechanism

$$
\begin{gathered}
\mathrm{C}_{2} \mathrm{H}_{2}+h v \rightarrow \mathrm{C}_{2} \mathrm{H}+\mathrm{H} \\
\mathrm{C}_{2} \mathrm{H}_{2}+\mathrm{C}_{2} \mathrm{H} \rightarrow \mathrm{C}_{4} \mathrm{H}_{2}+\mathrm{H} \\
\mathrm{C}_{4} \mathrm{H}_{2}+\mathrm{H} \stackrel{\mathrm{M}}{\rightarrow} \mathrm{C}_{4} \mathrm{H}_{3} \\
\mathrm{C}_{4} \mathrm{H}_{3}+\mathrm{C}_{2} \mathrm{H}_{2} \stackrel{\mathrm{M}}{\rightarrow} \mathrm{C}_{6} \mathrm{H}_{5} \\
\mathrm{C}_{6} \mathrm{H}_{5}+\mathrm{H}^{\mathrm{M}} \rightarrow \mathrm{C}_{6} \mathrm{H}_{6} \\
3 \mathrm{C}_{2} \mathrm{H}_{2} \rightarrow \mathrm{C}_{6} \mathrm{H}_{6}
\end{gathered} .
$$

In the BEN3 profile, this scheme competes with (S2) for benzene production in this region with the inclusion of $\mathrm{C}_{6} \mathrm{H}_{4}$ in the Wang and Frenklach [1994, 1997] scheme:

$$
\begin{gathered}
\mathrm{C}_{2} \mathrm{H}_{2}+h v \rightarrow \mathrm{C}_{2} \mathrm{H}+\mathrm{H} \\
\mathrm{C}_{2} \mathrm{H}_{2}+\mathrm{C}_{2} \mathrm{H} \rightarrow \mathrm{C}_{4} \mathrm{H}_{2}+\mathrm{H} \\
\mathrm{C}_{4} \mathrm{H}_{2}+\mathrm{H} \stackrel{\mathrm{M}}{\rightarrow} \mathrm{C}_{4} \mathrm{H}_{3} \\
\mathrm{C}_{4} \mathrm{H}_{3}+\mathrm{C}_{2} \mathrm{H}_{2} \rightarrow \mathrm{C}_{6} \mathrm{H}_{4}+\mathrm{H}, \\
\mathrm{C}_{6} \mathrm{H}_{4}+\mathrm{H} \stackrel{\mathrm{M}}{\rightarrow} \mathrm{C}_{6} \mathrm{H}_{5} \\
\mathrm{C}_{6} \mathrm{H}_{5}+\mathrm{H}^{\mathrm{M}} \rightarrow \mathrm{C}_{6} \mathrm{H}_{6} \\
3 \mathrm{C}_{2} \mathrm{H}_{2} \rightarrow \mathrm{C}_{6} \mathrm{H}_{6}
\end{gathered}
$$

which makes up $43 \%$ of non-recycled benzene production in the lower stratosphere. The acetylene addition-hydrogen abstraction mechanism also plays a minor role in benzene formation through the scheme:

$$
\begin{aligned}
& 2\left(\mathrm{C}_{2} \mathrm{H}_{2}+\mathrm{H} \stackrel{\mathrm{M}}{\rightarrow} \mathrm{C}_{2} \mathrm{H}_{3}\right) \\
& \mathrm{C}_{2} \mathrm{H}_{3}+\mathrm{C}_{2} \mathrm{H}_{3} \rightarrow \mathrm{C}_{4} \mathrm{H}_{6} \\
& \mathrm{C}_{4} \mathrm{H}_{6}+h v \rightarrow \mathrm{C}_{4} \mathrm{H}_{5}+\mathrm{H}, \\
& \mathrm{C}_{2} \mathrm{H}_{2}+\mathrm{C}_{4} \mathrm{H}_{5} \rightarrow \mathrm{C}_{6} \mathrm{H}_{6}+\mathrm{H} \\
& 3 \mathrm{C}_{2} \mathrm{H}_{2} \rightarrow \mathrm{C}_{6} \mathrm{H}_{6}
\end{aligned}
$$

involving the attachment of hydrogen atoms onto the phenyl radical $\left(\mathrm{C}_{6} \mathrm{H}_{5}\right)$. This scheme, however, only makes up about $1 \%$ of benzene production in the stratosphere. 


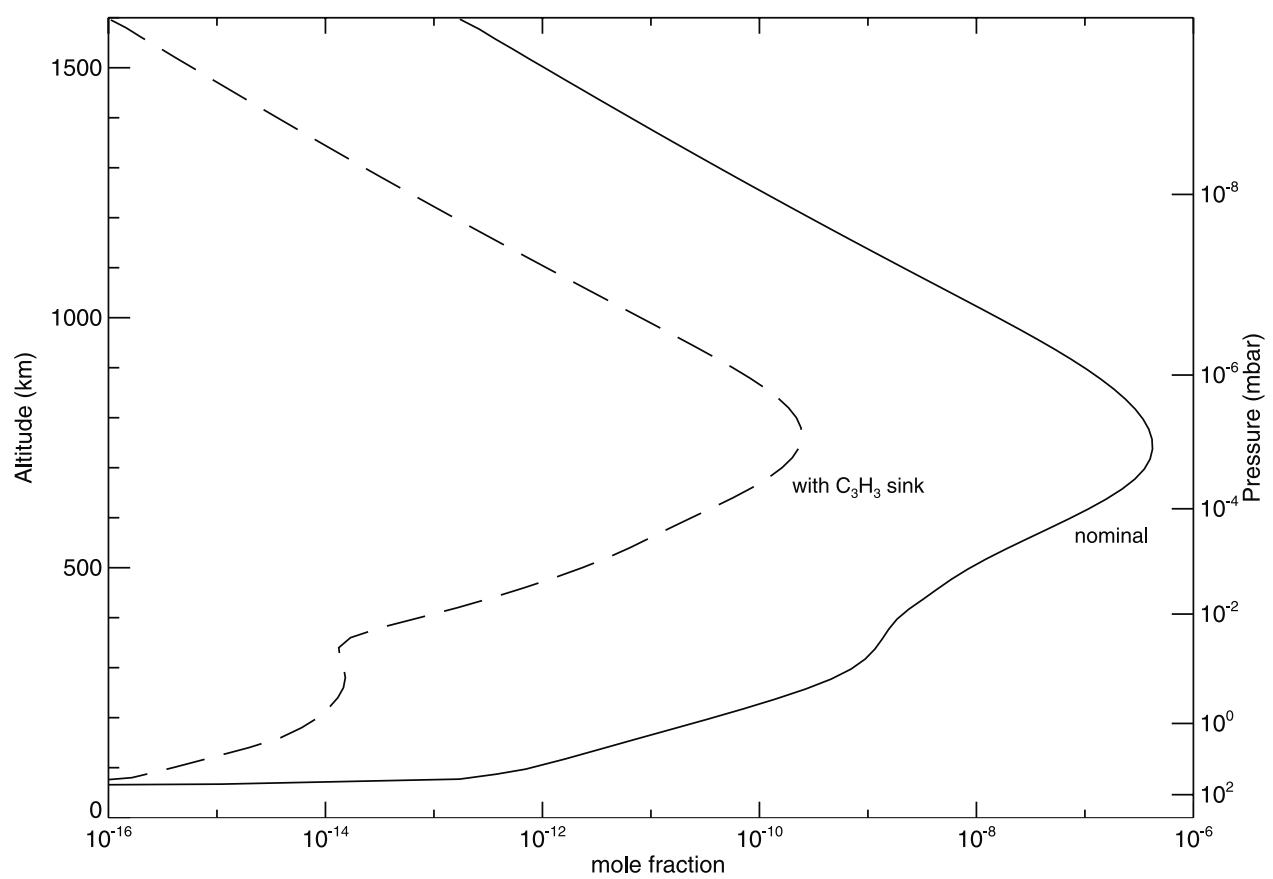

Figure 3. Benzene profile showing the effects of the Homann and Schweinfurth [1981] $\mathrm{C}_{3} \mathrm{H}_{3}$ sink. The solid line displays the nominal profile while the dashed line includes the $\mathrm{C}_{3} \mathrm{H}_{3}$ sink.

[17] For the metastable diacetylene pathway, we took the Arrington et al. [1998] relative rate constant calculation multiplied by the maximum collision rate for $\mathrm{k}\left(\mathrm{C}_{4} \mathrm{H}_{2}^{*}+\right.$ $\left.\mathrm{C}_{4} \mathrm{H}_{2}\right)=8.5 \times 10^{-12} \mathrm{~T}^{0.5} \mathrm{~cm}^{3} \mathrm{~s}^{-1}$, and took their relative product yields to obtain a rate coefficient for $(\mathrm{R} 4 \mathrm{a})$ of 4.14 $\times 10^{-12} \mathrm{~T}^{0.5} \mathrm{~cm}^{3} \mathrm{~s}^{-1}$. With this rate coefficient, we find this pathway to benzene to be negligible.

[18] With the benzene abundance so dependent on the propargyl radical, other propargyl sinks can inhibit benzene formation. Homann and Schweinfurth [1981], in their study of pathway to diacetylene formation, assumed a loss mechanism for $\mathrm{C}_{3} \mathrm{H}_{2}$ and $\mathrm{C}_{3} \mathrm{H}_{3}$ via acetylene:

$$
\begin{array}{cc}
\mathrm{C}_{3} \mathrm{H}_{2}+\mathrm{C}_{2} \mathrm{H}_{2} \rightarrow \text { products } & \mathrm{k}_{7}=4.98 \times 10^{-13} \mathrm{~cm}^{3} \mathrm{~s}^{-1} \\
\mathrm{C}_{3} \mathrm{H}_{3}+\mathrm{C}_{2} \mathrm{H}_{2} \rightarrow \text { products } & \mathrm{k}_{8}=2.0 \times 10^{-13} \mathrm{~cm}^{3} \mathrm{~s}^{-1}
\end{array}
$$

Rate coefficients were assigned for these reactions in their mechanism in order to account for the measured $\mathrm{C}_{3} \mathrm{H}_{4}$ and $\mathrm{C}_{4} \mathrm{H}_{2}$ in their study. Using these rates offers a large sink for $\mathrm{C}_{3} \mathrm{H}_{3}$ radical which reduces the abundance of benzene by three orders of magnitude, as shown in Figure 3. In this scenario, schemes (S3) and (S4) play a much larger role in benzene formation.

[19] Burcat and Dvinyaninov [1997] propose (R6) to form the linear- $\mathrm{C}_{5} \mathrm{H}_{5}$ molecule which is cyclized to form the cyclopentadienyl radical, but does not indicate an efficient path from this linear molecule to $\mathrm{C}_{6}$-molecules which would influence benzene. Thus, this path seems to potentially inhibit benzene formation. However, this study was conducted at temperatures exceeding $1000 \mathrm{~K}$. Alkemade and Homann [1989] in an attempt at measuring (R6) $(\mathrm{T}=623 \mathrm{~K})$ could not identify any products and established a rate coefficient upper limit of $1.66 \times 10^{-13} \mathrm{~cm}^{3} \mathrm{~s}^{-1}$. It is likely that (R5) and (R6) do not take place at a significant rate at Titan-like temperatures, allowing benzene to be formed in greater quantities.
[20] The possible effect of ion chemistry on the formation of benzene has also been examined. Including rate coefficients from McEwan et al. [1999] with the nominal scheme, a benzene profile is obtained, shown in Figure 4. This figure shows an enhancement of benzene in the ionosphere region above $700 \mathrm{~km}$, with the peak mole fraction increasing to 3.3 $\times 10^{-7}$, a slight enhancement over the nominal profile. The increase in the influence of this pathway is more pronounced higher in the ionosphere as electron dissociative recombination clearly controls benzene production (Figure 4). Column abundances for this ion case are shown in Table 2. Benzene is produced in this manner through nitrogen catalysis and the involvement of $\mathrm{H}_{2} \mathrm{CN}^{+}$, the most abundant ion in Titan's atmosphere, through

$$
\begin{aligned}
\mathrm{N}_{2}+h v & \rightarrow \mathrm{N}_{2}^{+}+e^{-} \\
\mathrm{N}_{2}^{+}+\mathrm{CH}_{4} & \rightarrow \mathrm{CH}_{3}^{+}+\mathrm{N}_{2}+\mathrm{H} \\
\mathrm{CH}_{3}^{+}+\mathrm{CH}_{4} & \rightarrow \mathrm{C}_{2} \mathrm{H}_{5}^{+}+\mathrm{H}_{2} \\
\mathrm{C}_{2} \mathrm{H}_{5}^{+}+\mathrm{HCN} & \rightarrow \mathrm{H}_{2} \mathrm{CN}^{+}+\mathrm{C}_{2} \mathrm{H}_{4} \\
\mathrm{H}_{2} \mathrm{CN}^{+}+\mathrm{C}_{4} \mathrm{H}_{2} & \rightarrow \mathrm{C}_{4} \mathrm{H}_{3}^{+}+\mathrm{HCN} \\
\mathrm{C}_{4} \mathrm{H}_{3}^{+}+\mathrm{C}_{2} \mathrm{H}_{2} & \rightarrow[c-] \mathrm{C}_{6} \mathrm{H}_{5}^{+}+h v \\
c-\mathrm{C}_{6} \mathrm{H}_{5}^{+}+\mathrm{H}_{2} & \rightarrow c-\mathrm{C}_{6} \mathrm{H}_{7}^{+}+h v \\
c-\mathrm{C}_{6} \mathrm{H}_{7}^{+}+e^{-} & \rightarrow \mathrm{C}_{6} \mathrm{H}_{6}+\mathrm{H} \\
2 \mathrm{CH}_{4}+\mathrm{C}_{2} \mathrm{H}_{2}+\mathrm{C}_{4} \mathrm{H}_{2} & \rightarrow \mathrm{C}_{6} \mathrm{H}_{6}+\mathrm{C}_{2} \mathrm{H}_{4}+2 \mathrm{H}
\end{aligned}
$$

[21] This scheme has a couple of caveats. $\mathrm{C}_{6} \mathrm{H}_{5}^{+}$exists in both cyclic and acyclic forms as it results from $\mathrm{C}_{2} \mathrm{H}_{2}$ addition [Scott et al., 1997]. Although $c-\mathrm{C}_{6} \mathrm{H}_{5}{ }^{+}$appears to be more reactive than its acyclic counterpart, the process and structure of this mechanism seems to be as yet unclear. McEwan et al. [1999] assumes that cyclization predominates, based on other experiments under three-body associative conditions. Another caution is the absence of other loss 

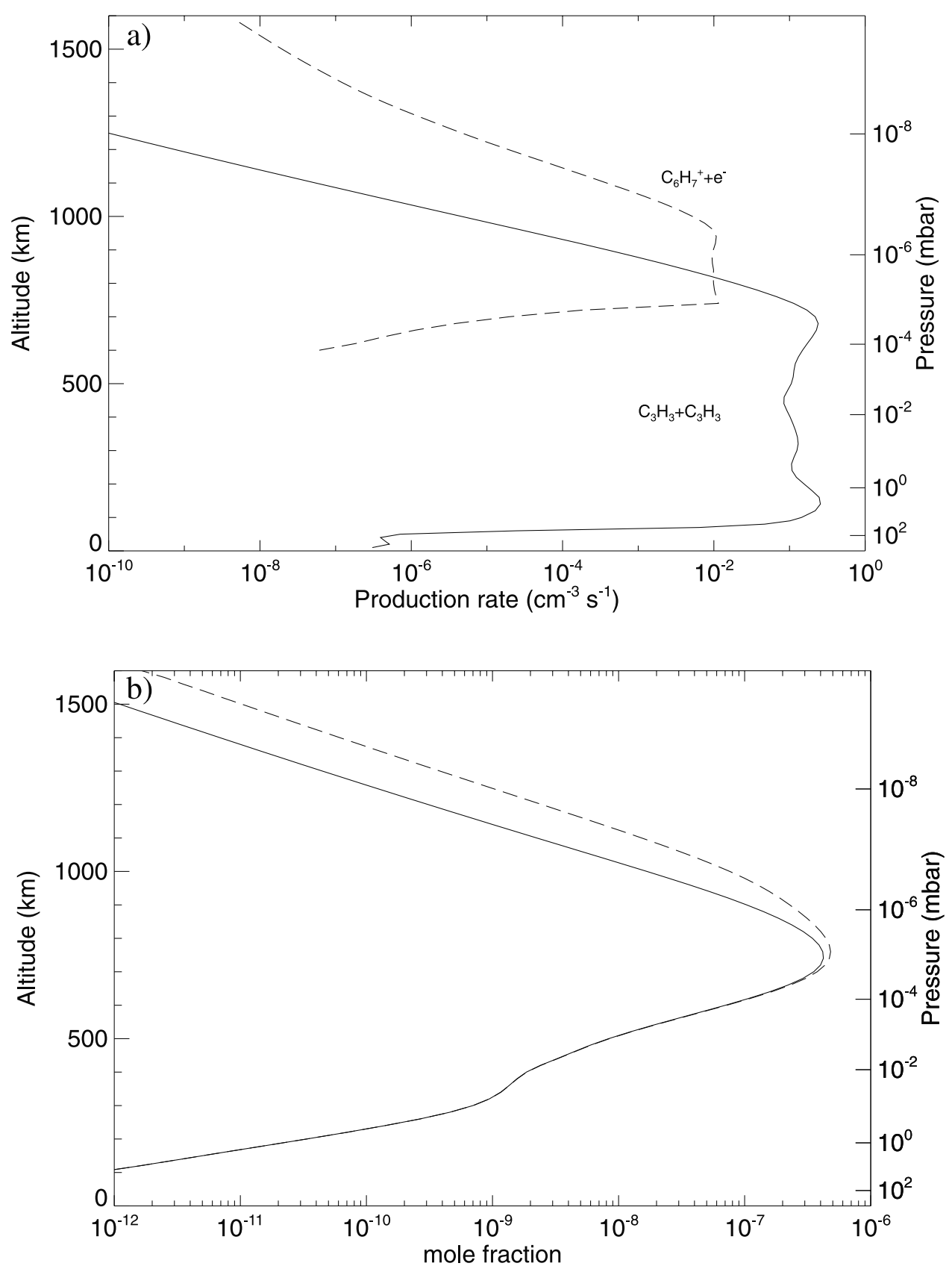

Figure 4. a) Production rate profiles of the ion case. The solid line shows the production rate for propargyl recombination and the dashed line shows the production rate for electron dissociative recombination. b) Comparison between the nominal profile and the ion pathway to benzene. The solid line displays the nominal profile and the dashed line displays the ion case profile.

mechanisms for $c-\mathrm{C}_{6} \mathrm{H}_{7}^{+}$. Although reactions with $\mathrm{H}$ and $\mathrm{H}_{2}$ have been shown not to take place [Anicich and McEwan, 1997], reactions with other molecules must be measured in order to accurately assess the significance of this pathway to benzene. However, it seems evident that ion chemistry does play a part in the upper atmosphere formation of benzene.

\section{Comparison With Observations}

[22] Benzene was not detected on Titan until recently from ISO observations with the Short Wavelength Spectrometer (SWS) around 14.85 micron. Indeed, thorough examination of the data acquired by this instrument by Coustenis et al. [2003] near $674 \mathrm{~cm}^{-1}$ showed that there was a significant improvement to the fit of the data when a benzene abundance was included in the model spectra (Figure 5).

[23] Because of problems in the fit of the nearby spectral regions this detection is tentative at this stage, but using line-by-line calculations, Coustenis et al. [2003] were able to simulate the emission observed in the $v_{4}$ band of benzene near $674 \mathrm{~cm}^{-1}$ and found the best fit with the data to correspond to a $\mathrm{C}_{6} \mathrm{H}_{6}$ abundance of $4 \pm 3 \times 10^{-10}$ when a uniform mole fraction profile above the saturation level was 


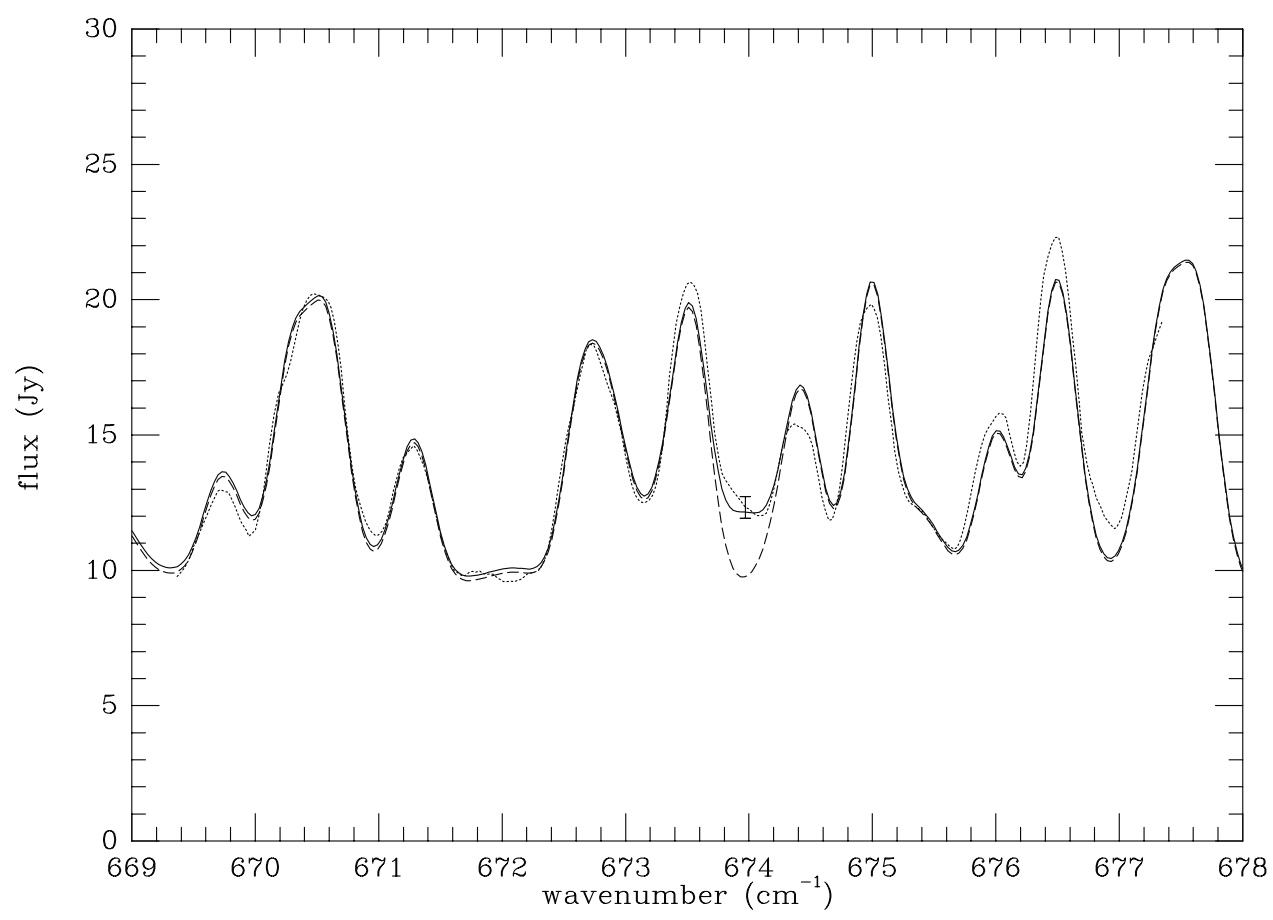

Figure 5. Comparison between ISO/SWS dedicated observations (dotted line) and calculations (dashed line) with a Titan atmospheric model in the $655-680 \mathrm{~cm}^{-1}$ region. This model shows lack of emission at wave numbers that correspond to the emission bands of benzene (centered at $674 \mathrm{~cm}^{-1}$ ). By adding a uniform benzene mixing ratio profile of $4 \pm 3 \times 10^{-10}$, or by using our vertical profile BEN3 multiplied by 2.5 to produce a synthetic spectrum (solid line), the fit is significantly improved in the benzenededicated SWS observation, covering the $669-678 \mathrm{~cm}^{-1}$ region.

used. The discrepancies in the fit around $676-677 \mathrm{~cm}^{-1}$ are not affected by the benzene signature in the $v_{4}$ band. This uniform profile corresponds to atmospheric levels between 0.2 and 20 mbar with the $\mathrm{C}_{6} \mathrm{H}_{6}$ contribution function peaking at 9 mbar, producing a column density for Titan above the 30 -mbar level of about $2.0 \pm 1.5 \times 10^{15}$ molecules $\mathrm{cm}^{-2}$. This benzene column density is compatible with the one inferred for Jupiter above the 50-mbar level from ISO measurements, but considerably higher (factor of 40) than the one found for Saturn above the 10mbar level [Bézard et al., 2001]. The mole fraction for benzene in Jupiter is close to that value (a few $10^{-10}$ for a vertical profile with a contribution function peaking around 7 mbar), whereas the Saturn mole fraction is an order of magnitude smaller at 3 mbar for one of the profiles suggested by Bézard et al. [2001, Figure 7].

[24] Coustenis et al. [2003] have also tested the vertical profiles for benzene produced in this work and found them to be compatible with the ISO data, assuming adjustments varying between 2.5 and 8 , although no real information on the abundance of benzene as a function of height could be obtained from the optically thin band involved here. Thus BEN3 increased by a factor of $3.0 \pm 0.5$ corresponds to the profile providing the easiest fit to the ISO data, while BEN1 and BEN2 need to be multiplied by $7.5 \pm 0.5$ and $6.5 \pm 0.5$, respectively. The nominal profile above 30 mbar produces a column density, which is shown in Table 2, an order of magnitude smaller than that derived with the uniform profile. However, above 3 mbar, just above the $\mathrm{C}_{6} \mathrm{H}_{6}$ contribution function peak, the calculated $\mathrm{C}_{6} \mathrm{H}_{6}$ nominal column density (BEN3) multiplied by $3.0 \pm 0.5$ is consistent with the derived uniform profile.

\section{Conclusions}

[25] The inception of aromatic chemistry and the formation of benzene in the atmosphere of Titan have been studied under a variety of scenarios. Through this study, aromatic chemistry has been found to possibly hold much significance in Titan atmospheric chemistry by means of benzene production. With an abundance of $3.9 \times 10^{-11}$ at $200 \mathrm{~km}(1$ mbar), peaking to $2.4 \times 10^{-7}$ at $720 \mathrm{~km}\left(2 \times 10^{-5} \mathrm{mbar}\right)$ for the nominal case, benzene may provide a pathway into the formation of higher-order PAHs and play a significant role in the mechanism responsible for Titan haze formation. This predicted abundance has been tentatively justified by the ISO detection of stratospheric benzene, matched by the nominal profile multiplied by the lower bound of 2.5.

[26] This study highlights the need for further study of aromatic mechanisms at lower temperatures, applicable to planetary atmospheres. In particular, kinetic studies of propargyl recombination, acetylene insertion into the $\mathrm{C}_{4} \mathrm{H}_{3}$ radical, and hydrogen addition into $\mathrm{C}_{6} \mathrm{H}_{4}$ and $\mathrm{C}_{6} \mathrm{H}_{5}$ compounds, involving rate determination and product identification at temperatures below $200 \mathrm{~K}$ would go far in elucidating the mechanisms responsible for benzene formation on Titan. In addition, continued investigation into the branching ratios of benzene photolysis as a function of wavelength as well as low-temperature kinetic examination of acetylene insertion into benzene and other loss mecha- 
nisms of benzene that contribute to the growth of PAHs will permit a better understanding of the benzene profile in Titan's atmosphere. Further study into the loss processes of the propargyl radical, particularly with acetylene at low temperatures, and ion chemistry involving aromatic compounds will also contribute to this understanding.

[27] Cassini/Huygens will provide an opportunity for detection of benzene in the stratosphere through the Composite Infrared Spectrometer (CIRS) and the Gas Chromatograph/Mass Spectrometer (GCMS). Furthermore, a contribution to benzene abundance in the upper atmosphere from ion sources may facilitate the detection of benzene through the INMS (Ion-Neutral Mass Spectrometer). Data from this mission will provide insight into the role of aromatic chemistry in the makeup of Titan's atmosphere.

[28] Acknowledgments. This research was supported by the NASA Planetary Atmospheres program and by the GCMS and ACP projects of the Cassini/Huygens mission.

\section{References}

Alkemade, U., and K. H. Homann, Formation of $\mathrm{C}_{6} \mathrm{H}_{6}$ isomers by recombination of propynyl, Z. Phys. Chem. Neue Folge, 161, 19-34, 1989.

Anicich, V. G., and M. J. McEwan, Ion-molecule chemistry in Titan's ionosphere, Planet. Space Sci., 45, 897-921, 1997.

Arrington, C. A., C. Ramos, A. D. Robinson, and T. S. Zwier, Aromatic ring-formation reactions of metastable diacetylene with 1, 3-butadiene, J. Phys. Chem., 102, 3315-3322, 1998.

Atkinson, D. B., and J. W. Hudgens, Rate coefficients for the propargyl radical self-reaction and oxygen addition reaction measured using ultraviolet cavity ring-down spectroscopy, J. Phys. Chem., 103, 4242-4252, 1999.

Atreya, S. K., S. G. Edgington, T. Encrenaz, H. Feuchtgruber, ISO observations of $\mathrm{C}_{2} \mathrm{H}_{2}$ on Uranus and $\mathrm{CH}_{3}$ on Saturn: Implications for atmospheric vertical mixing in the Voyager and ISO epochs, and a call for relevant laboratory measurements, Eur. Space Agency Spec. Publ., ESA, $S P-427,149-152,1999$.

Baulch, D. L., et al., Evaluated kinetic data for combustion modelling, J. Phys. Chem. Ref. Data, 21, 411-734, 1992.

Bézard, B., P. Drossart, T. Encrenaz, and H. Feuchtgruber, Benzene on the giant planets, Icarus, 154, 492-500, 2001.

Bittner, J. D., and J. B. Howard, Composition profiles and reaction mechanisms in a near-sooting premixed benzene/oxygen/argon flame, Symp. Int. Combust., 18, 1105-1116, 1981.

Burcat, A., and M. Dvinyaninov, Detailed kinetics of cyclopentadiene decomposition studied in a shock tube, Int. J. Chem. Kinet., 29, 505-514, 1997.

Buss, R. H., A. G. G. M. Tielens, M. Cohen, M. Werner, J. D. Bregman, and F. C. Witteborn, Infrared spectra of transition objects and the composition and evolution of carbon dust, Astrophys. J., 415, 250-257, 1993.

Callear, A. B., and G. B. Smith, Recurring chains following addition of atomic hydrogen to acetylene, J. Phys. Chem., 90, 3229-3237, 1986.

Clemett, S. J., C. R. Maechling, R. N. Zare, S. Messenger, C. M. O. Alexander, X. Gao, P. D. Swan, and R. M. Walker, Measurements of aromatic-hydrocarbons in interstellar graphite grains, 2, Molecular measurements, Meteoritics, 29, 458, 1994.

Cole, J. A., J. D. Bittner, J. P. Longwell, and J. B. Howard, Formation mechanisms of aromatic compounds in aliphatic flames, Combust. Flame, 56, 51-70, 1984

Colket, M. B., The pyrolysis of acetylene and vinylacetylene in a singlepulse shock tube, Symp. Int. Combust., 21, 851-864, 1986.

Coustenis, A., A. Salama, B. Schulz, S. Ott, E. Lellouch, T. Encrenaz, D. Gautier, and H. Feuchtgruber, Titan's atmosphere from ISO mid-infrared spectroscopy, Icarus, in press, 2003.

Encrenaz, T., P. Drossart, H. Feuchtgruber, E. Lellouch, B. Bézard, T. Fouchet, and S. K. Atreya, The atmospheric composition and structure of Jupiter and Saturn from ISO observations: A preliminary review, Planet. Space Sci., 47, 1225-1242, 1999.

Fahr, A., and A. Nayak, Kinetics and products of propargyl $\left(\mathrm{C}_{3} \mathrm{H}_{3}\right)$ radical self-reactions and propargyl-methyl cross-combination reactions, Int. J. Chem. Kinet., 32, 118-124, 2000.

Fahr, A., A. Laufer, and W. Braun, Reaction rate determinations of vinyl radical reactions with vinyl, methyl, and hydrogen atoms, J. Phys. Chem., 95, 3218-3224, 1991.

Frenklach, M., and E. D. Feigelson, Formation of polycyclic aromatic hydrocarbons in circumstellar envelopes, Astrophys. J., 341, 372-384, 1989.
Harris, S. J., A. M. Weiner, and R. J. Blint, Formation of small aromatic molecules in a sooting ethylene flame, Combust. Flame, 72, 91-109, 1988. Homann, K. H., and H. Schweinfurth, Kinetics and mechanism of hydrocarbon formation in the system $\mathrm{C}_{2} \mathrm{H}_{2} / \mathrm{O} / \mathrm{H}$, Ber. Bunsenges. Phys. Chem., $85,569-577,1981$

Kim, S. J., J. Caldwell, A. R. Rivolo, R. Wagener, and G. S. Orton, Infrared polar brightening on Jupiter, III, Spectrometry from the Voyager 1 IRIS experiment, Icarus, 64, 233-248, 1985.

McEwan, M. J., G. B. I. Scott, N. G. Adams, L. M. Babcock, R. Terzieva, and $\mathrm{E}$. Herbst, New $\mathrm{H}$ and $\mathrm{H}_{2}$ reactions with small hydrocarbon ions and their roles in benzene synthesis in dense interstellar clouds, Astrophys. J., 513, 287-293, 1999.

Miller, J. A., and C. F. Melius, Kinetic and thermodynamic issues in the formation of aromatic compounds in flames of aliphatic fuels, Combust. Flame, 91, 21-39, 1992.

Mimura, K., Synthesis of polycyclic aromatic hydrocarbons from benzene by impact shock: Its reaction mechanism and cosmochemical significance, Geochim. Cosmochim. Acta, 59, 579-591, 1995.

Morter, C. L., S. K. Farhat, J. D. Adamson, G. P. Glass, and R. F. Curl, Rate constant measurement of the recombination reaction $\mathrm{C}_{3} \mathrm{H}_{3}+\mathrm{C}_{3} \mathrm{H}_{3}$, J. Phys. Chem., 98, 7029-7035, 1994.

Moses, J. I., B. Bézard, E. Lellouch, G. R. Gladstone, H. Feuchtgruber, and M. Allen, Photochemistry of Saturn's atmosphere, I, Hydrocarbon chemistry and comparisons with ISO observations, Icarus, 143, 244-298, 2000.

Pantos, E., J. Philis, and A. Bolovinos, The extinction coefficient of benzene vapor in the region 4.6 to $36 \mathrm{eV}$, J. Mol. Spectrosc., 72, 36-43, 1978.

Rennie, E. E., C. A. F. Johnson, J. E. Parker, D. M. P. Holland, D. A. Shaw, and M. A. Hayes, A photoabsorption, photodissociation and photoelectron spectroscopy study of $\mathrm{C}_{6} \mathrm{H}_{6}$ and $\mathrm{C}_{6} \mathrm{D}_{6}$, Chem. Phys., 229, 107-123, 1998.

Sagan, C., B. N. Khare, W. R. Thompson, G. D. McDonald, M. R. Wing, J. L. Bada, V. D. Tuan, and E. T. Arakawa, Polycyclic aromatic hydrocarbons in the atmospheres of Titan and Jupiter, Astrophys. J., 414, 399$405,1993$.

Scott, G. B. I., D. A. Fairley, C. G. Freeman, M. J. McEwan, N. G. Adams, and L. C. Babcock, $\mathrm{C}_{\mathrm{m}} \mathrm{H}_{\mathrm{n}}^{+}$reactions with $\mathrm{H}$ and $\mathrm{H}_{2}$ : An experimental study, J. Phys. Chem., 101, 4973-4978, 1997.

Slagle, I. R., D. Gutman, J. W. Davies, and M. Pilling, Study of the recombination reaction $\mathrm{CH}_{3}+\mathrm{CH}_{3} \rightarrow \mathrm{C}_{2} \mathrm{H}_{6}$ I, Experiment, J. Phys. Chem., 92, 2455-2462, 1988.

Stein, S. E., J. A. Walker, M. M. Suryan, and A. Fahr, A new pathway to benzene in flames, Symp. Int. Combust., 23, 85-90, 1990.

Tielens, A. G. G. M., and S. B. Charnley, Circumstellar and interstellar synthesis of organic molecules, in Planetary and Interstellar Processes Relevant to the Origins of Life, edited by D. C. B. Whittet, pp. 23-51, Kluwer Acad., Norwell, Mass., 1997.

Wang, H., and M. Frenklach, Calculations of rate coefficients for the chemically activated reactions of acetylene with vinylic and aromatic radicals, J. Phys. Chem., 98, 11,465-11,489, 1994.

Wang, H., and M. Frenklach, A detailed kinetic modeling study of aromatics formation in laminar premixed acetylene and ethylene flames, Combust. Flame, 110, 173-221, 1997.

Weast, R. C., M. J. Astle, and W. H. Beyer, CRC Handbook of Chemistry and Physics, 67th ed., CRC Press, Boca Raton, Fla., 1987.

Weissman, M. A., and S. W. Benson, Rate parameters for the reactions of $\mathrm{C}_{2} \mathrm{H}_{3}$ and $\mathrm{C}_{4} \mathrm{H}_{5}$ with $\mathrm{H}_{2}$ and $\mathrm{C}_{2} \mathrm{H}_{2}$, J. Phys. Chem., 92, 4080-4084, 1988. Westmoreland, P. R., A. M. Dean, J. B. Howard, and J. P. Longwell, Forming benzene in flames by chemically activated isomerization, J. Phys. Chem., 93, 8171-8180, 1989.

Wilson, E. H., and S. K. Atreya, Sensitivity studies of methane photolysis and its impact on hydrocarbon chemistry in the atmosphere of Titan, J. Geophys. Res., 105, 20,263-20,273, 2000.

Wong, A.-S., A. Y. T. Lee, Y. L. Yung, and J. M. Ajello, Jupiter: Aerosol chemistry in the polar atmosphere, Astrophys. J., 534, L215-L217, 2000.

Yelle, R. V., D. F. Strobel, E. Lellouch, D. Gautier, Engineering models for Titan's atmosphere, Eur. Space Agency Spec. Publ., ESA, SP-1177, $243-$ 256, 1997.

Yokoyama, A., X. Zhao, E. J. Hintsa, R. E. Continetti, and Y. T. Lee, Molecular beam studies of the photodissociation of benzene at 193 and 248 nm, J. Chem. Phys., 92, 4222-4233, 1990.

Zwier, T. S., and M. Allen, Metastable diacetylene reactions as routes to large hydrocarbons in Titan's atmosphere, Icarus, 123, 578-583, 1996.

S. K. Atreya, Department of Atmospheric, Oceanic, and Space Sciences, University of Michigan at Ann Arbor, Ann Arbor, MI 48109-2143, USA. A. Coustenis, LESIA, Observatoire de Paris, Meudon 92195 Cedex, France.

E. H. Wilson, NASA/Jet Propulsion Laboratory, 4800 Oak Grove Drive, M/S 169-237, Pasadena, CA 91109-8099, USA. (eric.h.wilson@jpl.nasa. gov) 